\title{
Consistency of left ventricular hypertrophy diagnosed by electrocardiography and echocardiography: the Northern Shanghai Study
}

This article was published in the following Dove Medical Press journal: Clinical Interventions in Aging

\author{
Wei Zhangl,* \\ Yiwu Zhoul,* \\ Bin Bai' \\ Shikai Yu' \\ Jing Xiong' \\ Chen Chi' \\ Jiadela Teliewubai' \\ Jue $\mathrm{Li}^{2}$ \\ Jacques Blacher ${ }^{3}$ \\ Yi Zhang' \\ Yawei $\mathrm{Xu}{ }^{\prime}$ \\ 'Department of Cardiology, Shanghai \\ Tenth People's Hospital, School \\ of Medicine, Tongji University, \\ Shanghai, People's Republic of China; \\ ${ }^{2}$ Department of Prevention, School of \\ Medicine, Tongji University, Shanghai, \\ People's Republic of China; ${ }^{3}$ Diagnosis \\ and Therapeutic Center, Hôtel-Dieu, \\ Paris Descartes University, AP-HP, \\ Paris, France \\ *These authors contributed equally \\ to this work
}

\begin{abstract}
Background: Left ventricular hypertrophy $(\mathrm{LVH})$ is one of the preclinical manifestations of hypertensive target organ damage (TOD). However, it remains unclear which electrocardiographic criterion perform better in diagnosing $\mathrm{LVH}$.

Purpose: To investigate the consistency of LVH diagnosed by electrocardiography (ECG) and echocardiography (ECHO). Taking LVH by ECHO as reference, to compare three different ECG criteria (Sokolow-Lyon, Cornell and Cornell Product criteria) and find the best ECG indicator for identifying LVH in community-based elderly Chinese.

Patients and methods: Echocardiography and electrocardiography were applied to define LVH in 1789 elderly Chinese aged $>65$ years old in communities located at the northern Shanghai. Echocardiographic LVH (ECHO-LVH) was defined by left ventricular mass indexed for Body Surface Area (LVM/BSA) or for height ${ }^{2.7}\left(\mathrm{LVM} /\right.$ height $\left.^{2.7}\right)$. Electrocardiographic LVH (ECG-LVH) was defined by Sokolow-Lyon (SL), Cornell and Cornell Product (CP) criteria. ECHO-LVH was defined by $\mathrm{LVM} / \mathrm{BSA} \geq 125 \mathrm{~g} / \mathrm{m}^{2}$ in male or $\geq 110 \mathrm{~g} / \mathrm{m}^{2}$ in female (LVH1); $\mathrm{LVM} / \mathrm{BSA} \geq 115 \mathrm{~g} / \mathrm{m}^{2}$ in male, or $\geq 95 \mathrm{~g} / \mathrm{m}^{2}$ in female (LVH2) and LVM/height ${ }^{2.7} \geq 51 \mathrm{~g} / \mathrm{m}^{2.7}$ in male or $\geq 47 \mathrm{~g} / \mathrm{m}^{2.7}$ in female (LVH3). Results: As compared with SL and Cornell criteria, CP had the greatest correlation coefficient in the association with echocardiography-defined LVH, except for LVM/BSA in men. Of note, $\mathrm{CP}$ criterion had the greatest area under curve of ROC than Cornell criterion and the SL index, not only in total population but also in subgroups classified by blood pressure.
\end{abstract}

Conclusion: In ECG-LVH criteria, CP criterion complies better than SL index and Cornell criterion in assessing cardiac hypertrophy.

Keywords: left ventricular hypertrophy, electrocardiography, echocardiography, population study, accuracy

\section{Introduction}

Left ventricular hypertrophy (LVH) is one of the preclinical manifestations of hypertensive target organ damage (TOD). ${ }^{1}$ It is an independent risk factor of cardiovascular events and the diagnosis of LVH in the early stage is a strong predictor of morbidity. ${ }^{2-5}$ Long-term increased afterload may generate cardiac remodeling, which explains the formation mechanism of LVH.

Electrocardiography (ECG) and echocardiography (ECHO) can be applied to detect LVH in clinical practice. The diagnosis of LVH should preferably be made by ECHO because it can visually measure every parameter of cardiac structure in a noninvasive method. Furthermore, its high sensitivity and specificity make it a golden standard for the LVH detection. However, many conditions have restricted ECHO application in routine clinical practice, including operators' uneven levels and high expense.
Correspondence: Yi Zhang; Yawei Xu Department of Cardiology, Shanghai Tenth People's Hospital, School of Medicine, Tongji University, 30I Yanchang Road, Shanghai 200072, People's Republic of China Tel +8618917686332 Fax +86 21 66307239 Email yizshcn@gmail.com; xuyaweicn@aliyun.com 
The 12-lead resting ECG, another noninvasive method for detecting LVH, on the other hand, is more convenient, economic, and suitable for screening in a large scope.

More than 30 ECG criteria have been invented to define LVH over the past decades, ${ }^{6}$ including Lewis voltage, Gubner-Ungerleider voltage, RaVL, Romhilt-Estes score, left ventricular strain, RV6:RV5 ratio, Framingham criterion, Perugia criterion, and so on. But a few of them are still used in routine clinical practice. For instance, Sokolow et al developed Sokolow voltage to detect LVH in 1949 for the first time and it was widely used in the past. ${ }^{7}$ Lyon and Rappaport developed the method successively. SokolowLyon (SL) index is a classical approach to define LVH, and it calculates the sum of QRS voltage of S wave in V1 and R wave in V5 or V6. Some investigators pointed out that QRS duration is an independent predictor of $\mathrm{LVH}^{8}$ as a result, Cornell criterion and Cornell voltage-duration product (CP) were developed. The Cornell criterion means $\mathrm{S}$ wave in V3 plus $\mathrm{R}$ wave in aVL, and the CP criterion means Cornell criterion multiplied by the QRS duration.

In some studies, it was indicated that Cornell and CP criteria performed better than the SL index, ${ }^{9}$ whereas some studies tend to deliver a different opinion. ${ }^{10,11}$ It remains unclear which ECG criterion shows better reasoning in diagnosing LVH. Considering most ECG criteria have been established in the Caucasian, we aim to compare three different ECG criteria, taking LVH by ECHO as reference, to find out the best ECG indicator for identifying LVH in a communitybased elderly Chinese.

\section{Materials and methods Study design and subjects}

The Northern Shanghai Study (NSS) is a prospective population study with 1,789 community-dwelling elderly Chinese aged $>65$ years old. A systematic cardiovascular risk was conducted. Individuals who met the following eligible criteria were enrolled for this study: 1) those who are aged $>65$ years of age (based on birthday in their identity card); 2) those who volunteer to sign an informed consent; 3) long-term residents in northern part of Shanghai. Individual is excluded if he or she is: 1) unwilling to participate in the clinical study; 2) suffering from severe cardiac disease (New York Heart Association IV) or end-stage renal disease (Chronic kidney disease stage 4 or above); 3 ) diagnosed with cancer with life expectancy of less than 5 years; 4) developed stroke within 3 months; 5) suffering from other diseases to quit the study; 6) against the protocol; and 7) losing contact with laboratory staff. A total of 1,758 participants out of 1,789 subjects of NSS were included in the study, with 31 excluded because of absence of data. Subjects were notified both through phone calls and local neighborhood committees. Each subject was asked to undergo laboratory and clinical tests at either the Tenth People's Hospital of Tongji University or in the communities. The operators of ECG and ECHO were well-trained and we would readily test again if it was necessary to ensure accuracy of the data obtained from ECG and ECHO. All participants signed the informed consent. The protocol of the present study was approved by the ethics committee of the Shanghai Tenth People's Hospital. The study was conducted in accordance with the Declaration of Helsinki.

\section{ECG}

A 12-lead resting ECG was recorded at $25 \mathrm{~mm} / \mathrm{s}$ and $1 \mathrm{mV} / \mathrm{cm}$ standardization with equipment that have frequency response characteristics conforming to the recommendations of the American Heart Association. ${ }^{12}$ Electrocardiographic QRS wave voltage was detected in this study. Parameters include the voltage of the S wave of the leads V1 (SV1) and V3 (SV3), R wave of lead V5 (RV5) and aVL (RaVL), and the duration of QRS wave. Several electrocardiographic indices, namely SL index, Cornell criterion, and Cornell QRS duration product, were applied to assess high voltage of left ventricle to diagnose LVH. LVH was diagnosed as $\mathrm{SV} 1+\mathrm{RV} 5 \geq 3.5 \mathrm{mV}$ for SL index, ${ }^{7} \mathrm{SV} 3+\mathrm{RaVL} \geq 2.8 \mathrm{mV}$ in males and $\geq 2.0 \mathrm{mV}$ in females for Cornell criterion, ${ }^{13}$ and $(\mathrm{SV} 3+\mathrm{RaVL}) \times \mathrm{QRS}$ duration $\geq 244 \mathrm{mV} / \mathrm{ms}$ in males and $(\mathrm{SV} 3+\mathrm{RaVL}+0.6) \times \mathrm{QRS}$ duration $\geq 244 \mathrm{mV} / \mathrm{ms}$ in females for CP criterion. ${ }^{14}$

\section{$\mathrm{ECHO}$}

Echocardiographic measurement was performed by one sonographer who was blind to other data. Interventricular septum (IVS), left ventricular internal diameter (LVID), and posterior wall thickness (PWT) were measured, and left ventricular mass (LVM) was calculated using the American Society of Echocardiography (ASE) recommended formula:

$$
\begin{aligned}
\operatorname{LVM}(\mathrm{g})= & 0.8 \times 1.04 \times([\mathrm{IVS}+\mathrm{LVID}+\mathrm{PWT}] \\
& 3-\mathrm{LVID} 3)+0.6^{15}
\end{aligned}
$$

LVM was standardized by body surface area (BSA) and body height ${ }^{2.7}$ as LVM/BSA and LVM/height, ${ }^{2.7}$ respectively. LVH was diagnosed as LVM/BSA $>95 \mathrm{~g} / \mathrm{m}^{2}$ in females and $>115 \mathrm{~g} / \mathrm{m}^{2}$ in males ${ }^{15}$ as per the novel ASE criterion, $\mathrm{LVM} / \mathrm{BSA}>110 \mathrm{~g} / \mathrm{m}^{2}$ in females and $>125 \mathrm{~g} / \mathrm{m}^{2}$ in males ${ }^{1}$ according to the former ASE criterion, and LVM/ height $>51 \mathrm{~g} / \mathrm{m}^{2.7}$ in males and $>47 \mathrm{~g} / \mathrm{m}^{2.7}$ in females ${ }^{16}$ by other criteria. 


\section{Statistical analyses}

All data statistics were analyzed using SAS software, version 9.3 (SAS Institute, Cary, NC, USA) and SigmaPlot software, version 12.5 (Systat Software, Inc., San Jose, CA, USA). All measured values were reported as means \pm SD for continuous variables, numbers and percentages in parenthesis for categorical variables. Pearson's correlation coefficients were used to evaluate the degree of correlation between the three ECG criteria and the two indexed LVMs, namely LVM/BSA and LVM/height ${ }^{2.7}$, and chi-squared test was used to analyze the categorical variables. Fisher transformation analysis was conducted to compare the correlation coefficients. Receiver operating characteristic (ROC) curves and the areas under the curves analyses were conducted to compare the sensitivity and specificity for the three ECG criteria using conventional cut-off values. $P<0.05$ was considered statistical significance.

\section{Results}

\section{Characteristics of participants}

Characteristics of participants by gender are shown in Table 1, including conventional cardiovascular risk factors, hypertensive TOD, and ECG and ECHO parameters. Among 1,758 participants, 784 (44.6\%) were men, of which 336 (19.1\%) participants were suffering from diabetes, and 921 (52.4\%) from hypertension. Men, compared with women, were significantly taller $(164.4 \pm 6.1$ vs $154.8 \pm 5.7 \mathrm{~cm}$, $P<0.001)$, and had higher BSA ( $1.76 \pm 0.15$ vs $1.58 \pm 0.14 \mathrm{~m}^{2}$, $P<0.001)$, S wave amplitude in V3 lead $(0.82 \pm 0.46$ vs $0.65 \pm 0.42 \mathrm{mV}, P<0.001)$, QRS duration $(95.90 \pm 15.35$ vs $87.47 \pm 12.81 \mathrm{~ms}, P<0.001)$, SL index $(2.61 \pm 0.85$ vs $2.31 \pm 0.73, P<0.001)$, Cornell criterion $(1.23 \pm 0.57$ vs $1.08 \pm 0.53)$, PWT $(9.27 \pm 1.57$ vs $8.96 \pm 1.54 \mathrm{~mm}, P<0.001)$, LVID (47.90 \pm 7.05 vs $45.75 \pm 6.43 \mathrm{~mm}, P<0.001)$, and LVM (161.0 \pm 57.1 vs $143.1 \pm 48.1 \mathrm{~g}, P<0.001)$, but lower CP criterion $(118.8 \pm 64.7$ vs $147.5 \pm 53.1 \mathrm{mV} / \mathrm{ms}, P<0.001)$ and LVM/height ${ }^{2.7}(40.8 \pm 14.3$ vs $44.2 \pm 15.5, P<0.001)$.

Characteristics of participants by hypertensive status are shown in Table 2. All observation indices, such as age, $\mathrm{R}$ wave amplitude in lead aVL, S wave amplitude in lead V3, QRS duration, SL index, Cornell criterion, CP criterion, IVS, PWT, LVID, LV, LVM/BSA, and LVM/height ${ }^{2.7}$ had significantly greater value in hypertensive participants $(P<0.05)$.

Table I Characteristics of participants by gender

\begin{tabular}{|c|c|c|c|c|}
\hline Characteristics & $\begin{array}{l}\text { Overall } \\
(n=I, 758)\end{array}$ & $\begin{array}{l}\text { Men } \\
(n=784)\end{array}$ & $\begin{array}{l}\text { Women } \\
(n=974)\end{array}$ & P-value \\
\hline Age, years & $71.4 \pm 6.1$ & $71.4 \pm 6.0$ & $71.4 \pm 6.1$ & 0.88 \\
\hline Body height, cm & $160.0 \pm 8.3$ & $166.4 \pm 6.1$ & $154.8 \pm 5.7$ & $<0.001$ \\
\hline Body weight, kg & $62.5 \pm 10.6$ & $67.6 \pm 10.0$ & $58.3 \pm 9.1$ & $<0.001$ \\
\hline $\mathrm{BMI}, \mathrm{kg} / \mathrm{m}^{2}$ & $23.9 \pm 3.5$ & $23.9 \pm 3.2$ & $23.9 \pm 3.6$ & 0.81 \\
\hline $\mathrm{BSA}, \mathrm{m}^{2}$ & $1.66 \pm 0.17$ & $1.76 \pm 0.15$ & $1.58 \pm 0.14$ & $<0.001$ \\
\hline $\mathrm{SBP}, \mathrm{mmHg}$ & $134.5 \pm 17.7$ & $134.6 \pm 16.7$ & $134.4 \pm 18.4$ & 0.80 \\
\hline $\mathrm{DBP}, \mathrm{mmHg}$ & $78.90 \pm 9.2$ & $79.9 \pm 9.3$ & $78.1 \pm 9.0$ & $<0.001$ \\
\hline Diabetes, n (\%) & $336(19.1)$ & $146(18.6)$ & $190(19.5)$ & 0.65 \\
\hline Hypertension, n (\%) & $921(52.4)$ & $421(53.8)$ & $500(5 \mathrm{l} .3)$ & 0.31 \\
\hline \multicolumn{5}{|c|}{ ECG parameters and indices } \\
\hline RaVL, mV & $0.42 \pm 0.29$ & $0.4 I \pm 0.30$ & $0.43 \pm 0.28$ & 0.14 \\
\hline $\mathrm{SV} 3, \mathrm{mV}$ & $0.72 \pm 0.44$ & $0.82 \pm 0.46$ & $0.65 \pm 0.42$ & $<0.001$ \\
\hline QRS duration, ms & $91.23 \pm 14.61$ & $95.90 \pm 15.35$ & $87.47 \pm 12.81$ & $<0.001$ \\
\hline $\mathrm{SL}$ index, $\mathrm{mV}$ & $2.44 \pm 0.80$ & $2.61 \pm 0.85$ & $2.31 \pm 0.73$ & $<0.001$ \\
\hline Cornell criterion, $\mathrm{mV}$ & $1.15 \pm 0.55$ & $1.23 \pm 0.57$ & $1.08 \pm 0.53$ & $<0.001$ \\
\hline $\mathrm{CP}$ criterion, $\mathrm{mV} / \mathrm{ms}$ & $134.7 \pm 60.3$ & $18.8 \pm 64.7$ & $147.5 \pm 53.1$ & $<0.001$ \\
\hline \multicolumn{5}{|c|}{ ECHO parameters and indices } \\
\hline IVS, mm & $9.47 \pm 1.87$ & $9.61 \pm 1.94$ & $9.38 \pm 1.81$ & 0.011 \\
\hline PWT, mm & $9.10 \pm 1.56$ & $9.27 \pm 1.57$ & $8.96 \pm 1.54$ & $<0.0001$ \\
\hline LVID, mm & $46.71 \pm 6.80$ & $47.90 \pm 7.05$ & $45.75 \pm 6.43$ & $<0.0001$ \\
\hline LVM, g & $15|.| \pm 53 . \mid$ & $161.0 \pm 57.1$ & $\mid 43.1 \pm 48.1$ & $<0.0001$ \\
\hline LVM/BSA, g/m² & $90.5 \pm 28.9$ & $90.8 \pm 29.7$ & $90.3 \pm 28.3$ & 0.74 \\
\hline LVM/height $^{2.7}, \mathrm{~g} / \mathrm{m}^{2.7}$ & $42.7 \pm 15.1$ & $40.8 \pm 14.3$ & $44.2 \pm 15.5$ & $<0.0001$ \\
\hline
\end{tabular}

Notes: Data means \pm SD or numbers with percentages in parenthesis. Student's t-test and chi-squared analysis were conducted for the comparison of continuous and dichotomized variables between men and women.

Abbreviations: BMI, body mass index; BSA, body surface area; CP, Cornell Product; ECG, electrocardiography; ECHO, echocardiography; height ${ }^{2.7}$, LVM indexed for 2.7 power of body height; IVS, interventricular septum; LVID, left ventricular internal diameter; LVM, left ventricular mass; LVMI/BSA, LVM indexed for BSA; LVMI/PWT, LVM indexed for posterior wall thickness; PWT, posterior wall thickness; RaVL, R wave of lead aVL; SL, Sokolow-Lyon; SV3, S wave of the leads V3. 
Table 2 Characteristics of participants by hypertensive status

\begin{tabular}{|c|c|c|c|c|}
\hline Characteristics & $\begin{array}{l}\text { Overall } \\
(n=I, 757)\end{array}$ & $\begin{array}{l}\text { Hypertension } \\
(n=92 I)\end{array}$ & $\begin{array}{l}\text { No hypertension } \\
(n=836)\end{array}$ & $P$-value \\
\hline Age, years & $71.4 \pm 6.1$ & $72.0 \pm 6.2$ & $70.8 \pm 5.8$ & $<0.001$ \\
\hline \multicolumn{5}{|c|}{ ECG parameters and indices } \\
\hline $\mathrm{RaVL}, \mathrm{mV}$ & $0.42 \pm 0.29$ & $0.46 \pm 0.30$ & $0.38 \pm 0.26$ & $<0.001$ \\
\hline $\mathrm{SV} 3, \mathrm{mV}$ & $0.72 \pm 0.44$ & $0.77 \pm 0.47$ & $0.68 \pm 0.42$ & $<0.001$ \\
\hline QRS duration, ms & $91.22 \pm|4.6|$ & $91.88 \pm 15.26$ & $90.48 \pm 13.82$ & 0.044 \\
\hline $\mathrm{SL}$ index, $\mathrm{mV}$ & $2.44 \pm 0.80$ & $2.54 \pm 0.84$ & $2.33 \pm 0.74$ & $<0.001$ \\
\hline Cornell criterion, $\mathrm{mV}$ & $1.15 \pm 0.55$ & $1.23 \pm 0.58$ & $1.06 \pm 0.5 \mathrm{I}$ & $<0.001$ \\
\hline $\mathrm{CP}$ criterion, $\mathrm{mV} / \mathrm{ms}$ & $134.7 \pm 60.3$ & $143.0 \pm 65.2$ & $125.5 \pm 52.8$ & $<0.001$ \\
\hline \multicolumn{5}{|c|}{ ECHO parameters and indices } \\
\hline IVS, mm & $9.49 \pm 1.87$ & $9.79 \pm 1.96$ & $9.15 \pm 1.71$ & $<0.001$ \\
\hline PWT, mm & $9.10 \pm 1.56$ & $9.30 \pm 1.62$ & $8.88 \pm 1.46$ & $<0.001$ \\
\hline LVID, mm & $46.70 \pm 6.79$ & $47.73 \pm 6.88$ & $45.57 \pm 6.52$ & $<0.001$ \\
\hline LVM, g & $|5| .0 \pm 53.0$ & $161.8 \pm 55.6$ & $139.1 \pm 47.2$ & $<0.001$ \\
\hline LVM/BSA, $g / m^{2}$ & $90.5 \pm 28.9$ & $95.7 \pm 29.8$ & $84.7 \pm 26.7$ & $<0.001$ \\
\hline LVM/height ${ }^{2.7}, \mathrm{~g} / \mathrm{m}^{2.7}$ & $42.7 \pm 15.1$ & $45.7 \pm 15.3$ & $39.3 \pm 14.1$ & $<0.001$ \\
\hline
\end{tabular}

Abbreviations: BSA, body surface area; CP, Cornell Product; ECG, electrocardiography; ECHO, echocardiography; IVS, interventricular septum; LVID, left ventricular internal diameter; height ${ }^{2.7}$, LVM indexed for 2.7 power of body height; LVM, left ventricular mass; PWT, posterior wall thickness; RaVL, R wave of lead aVL; SL, SokolowLyon; SV3, S wave of the leads V3.

\section{Correlations between ECG and ECHO parameters}

As shown in Table 3, SL, Cornell, and CP parameters were all significantly correlated with LVM/BSA in total population, in both men and women (all $P \leq 0.01$ ). There were no significant differences in correlation coefficients among those parameters by the Fisher transformation analysis. As for LVH parameter and LVM/height ${ }^{2.7}$, all the three ECG parameters were significantly correlated in total population, in both men and women $(P<0.01)$, except for the association of LVM/height ${ }^{2.7}$ with SL index in females $(P=0.09)$.

\section{Discrepancies in the diagnosis of LVH by ECG and ECHO}

In Table 4, echocardiograph-diagnosed LVH is defined by LVM/BSA $\geq 125 \mathrm{~g} / \mathrm{m}^{2}$ in males and $\geq 110 \mathrm{~g} / \mathrm{m}^{2}$ in females as LVH1, by LVM/BSA $\geq 115 \mathrm{~g} / \mathrm{m}^{2}$ in males and $\geq 95 \mathrm{~g} / \mathrm{m}^{2}$ in females as LVH2, and by LVM/height ${ }^{2.7} \geq 51 \mathrm{~g} / \mathrm{m}^{2.7}$ in males and $\geq 47 \mathrm{~g} / \mathrm{m}^{2.7}$ in females as LVH3. In order to determine whether the Chinese method is superior to the commonly used SL criterion, we conducted SL-China criterion as well. Electrocardiograph-diagnosed $\mathrm{LVH}$ is defined by $\mathrm{SV} 1+$ $\mathrm{RV} 5 \geq 4.0 \mathrm{mV}$ in males and $\geq 3.5 \mathrm{mV}$ in females by the

Table 3 Correlation coefficient $(R)$ between the electrocardiographic and echocardiographic parameters for the detection of LVH in total participants, in both males and females

\begin{tabular}{|c|c|c|c|c|c|c|}
\hline \multirow[t]{2}{*}{ Index } & \multicolumn{2}{|c|}{ SL (SVI + RV5) } & \multicolumn{2}{|c|}{ Cornell (SV3 + RaVL) } & \multicolumn{2}{|c|}{$\mathrm{CP}(\mathrm{SV} 3+\mathrm{RaVL}) \times \mathbf{Q R S}$ duration } \\
\hline & $R$ & $P$-value & $R$ & $P$-value & $\boldsymbol{R}$ & $P$-value \\
\hline \multicolumn{7}{|c|}{ LVM/BSA } \\
\hline Total & 0.15 & $<0.001$ & 0.16 & $<0.001$ & 0.18 & $<0.001$ \\
\hline Male & 0.23 & $<0.001$ & 0.17 & $<0.001$ & 0.21 & $<0.001$ \\
\hline Female & 0.09 & $<0.01$ & 0.15 & $<0.001$ & 0.16 & $<0.001$ \\
\hline \multicolumn{7}{|c|}{ LVM/height $^{2.7}$} \\
\hline$\overline{T \text { Total }}$ & 0.09 & $<0.001$ & 0.15 & $<0.001$ & 0.21 & $<0.001$ \\
\hline Male & 0.20 & $<0.001$ & 0.17 & $<0.001$ & 0.21 & $<0.001$ \\
\hline Female & 0.05 & 0.091 & 0.17 & $<0.001$ & 0.17 & $<0.001$ \\
\hline
\end{tabular}

Note: Pearson's correlation analysis was applied between the electrocardiographic and echocardiographic parameters for the detection of LVH in total participants, in both males and females.

Abbreviations: BSA, body surface area; CP, Cornell Product; LVM, left ventricular mass; RaVL, R wave of lead aVL; RV5, R wave of lead V5; SL, Sokolow-Lyon; SVI, S wave of the leads VI; SV3, S wave of the leads V3. 
Table 4 Chi-squared test between LVH diagnosed by ECG and by ECHO

\begin{tabular}{|c|c|c|c|c|c|c|}
\hline \multirow[t]{2}{*}{ Index } & \multicolumn{2}{|c|}{$\begin{array}{l}\text { LVHI: LVM/BSA } \\
M \geq I 25 \mathrm{~g} / \mathrm{m}^{2}, F \geq 110 \mathrm{~g} / \mathrm{m}^{2}\end{array}$} & \multicolumn{2}{|c|}{$\begin{array}{l}\text { LVH2: LVM/BSA } \\
M \geq I 15 \mathrm{~g} / \mathrm{m}^{2}, F \geq 95 \mathrm{~g} / \mathrm{m}^{2}\end{array}$} & \multicolumn{2}{|c|}{$\begin{array}{l}\text { LVH3: LVM/height } 2.7 \\
M \geq 5 \mathrm{I} / \mathrm{m}^{2.7}, \mathrm{~F} \geq 47 \mathrm{~g} / \mathrm{m}^{2.7}\end{array}$} \\
\hline & $\chi^{2}$ & $P$-value & $\chi^{2}$ & $P$-value & $\chi^{2}$ & $P$-value \\
\hline \multicolumn{7}{|l|}{ LVH diagnosed by ECHO } \\
\hline SL-China $(M \geq 4.0 \mathrm{mV}, \mathrm{F} \geq 3.5 \mathrm{mV})$ & 24.15 & $<0.001$ & 16.00 & $<0.001$ & 15.99 & $<0.001$ \\
\hline$S L(M / F \geq 3.5 \mathrm{mV})$ & 14.34 & $<0.001$ & 7.52 & $<0.01$ & 9.67 & $<0.01$ \\
\hline Cornell $(\mathrm{M} \geq 2.8 \mathrm{mV}, \mathrm{F} \geq 2.0 \mathrm{mV})$ & 5.92 & 0.02 & 4.30 & 0.04 & 5.51 & 0.02 \\
\hline $\mathrm{CP}(\mathrm{M} / \mathrm{F} \geq 244 \mathrm{mV} / \mathrm{ms})$ & 2.71 & 0.10 & 5.10 & 0.02 & 9.23 & $<0.01$ \\
\hline
\end{tabular}

Abbreviations: BSA, body surface area; CP, Cornell Product; ECG, electrocardiography; ECHO, echocardiography; F, female; LVH, left ventricular hypertrophy; LVM, left ventricular mass; LVHI, LVH diagnosed by LVM indexed for BSA (LVMI $\geq 125 \mathrm{~g} / \mathrm{m}^{2}$ in males and $\geq 110 \mathrm{~g} / \mathrm{m}^{2}$ in females); LVH2, LVH diagnosed by LVM indexed for BSA (LVMI $\geq 115 \mathrm{~g} / \mathrm{m}^{2}$ in males and $\geq 95 \mathrm{~g} / \mathrm{m}^{2}$ in females); LVH3, LVH diagnosed by LVM indexed for body height ${ }^{2.7}$ (LVMI2 $\geq 51 \mathrm{~g} / \mathrm{m}^{2.7}$ in males and $\geq 47 \mathrm{~g} / \mathrm{m}^{2.7}$ in females); M, male; SL, Sokolow-Lyon.

SL-China criterion, by SV1 + RV5 $\geq 3.5 \mathrm{mV}$ irrespective of genders for SL criterion, by SV3 $+\mathrm{RaVL} \geq 2.8 \mathrm{mV}$ in males and $\geq 1.0 \mathrm{mV}$ in females for Cornell criterion, and by (SV3+ $\mathrm{RaVL}) \times \mathrm{QRS}$ duration $\geq 244 \mathrm{mV} / \mathrm{ms}$ in males and (SV3 + $\mathrm{RaVL}+6) \times \mathrm{QRS}$ duration $\geq 244 \mathrm{mV} / \mathrm{ms}$ in females for $\mathrm{CP}$ criterion. Significant discrepancies were found between LVH diagnosed by the Cornell criterion and LVH1 $(P=0.02)$, between LVH diagnosed by the Cornell criterion and LVH2 $(P=0.04)$, between LVH diagnosed by the CP criterion and LVH2 $(P=0.02)$, and between LVH diagnosed by the CP criterion and LVH3 $(P<0.01)$. Of note, LVH diagnosed by the SL-China criterion and SL criterion were significantly and consistently different from LVH1, LVH2, and LVH3 (all $P<0.01$ ); furthermore, SL criterion was slightly superior to SL-China criterion.

\section{Area under receiver operating characteristic (ROC) curve}

In Figure 1, the ROC curve is applied to estimate the diagnostic value of CP criterion compared to Cornell and SL in detecting LVH. As shown in Figure 1, CP criterion has the largest area under curve, not only in total population but also in subgroup classified by hypertension.

\section{Discussion}

In this study, three commonly used ECG criteria, the SL index, Cornell criterion, and CP criterion, were compared for detecting $\mathrm{LVH}$ in a large community-based elderly population located in the northern part of Shanghai, taking echocardiograph-defined LVH as reference. The major finding of this study was that $\mathrm{CP}$ criterion is superior to SL index and Cornell criterion for LVH assessment.

Two LVM indices were determined by echocardiograph in this study, namely, LVM/BSA and LVH/height ${ }^{2.7}$. The index of LVM to height ${ }^{2.7}$ was supposed to be a more sensitive one for estimating LVH. ${ }^{17}$ Moreover, the index of LVM to BSA was implemented as well. As shown in Table 1, there was no significant difference of LVM/BSA between genders ( $P=0.54$ ), whereas the difference of $\mathrm{LVM} /$ height $^{2.7}$ between genders is significant $(P<0.001)$. On the contrary, previous study by Simone et $\mathrm{al}^{17}$ and Park et $\mathrm{al}^{18}$ reported the opposite results. The difference may rely on different populations.

Okin et al, ${ }^{8}$ Hsieh et al, ${ }^{4}$ Molly et al,,${ }^{14}$ Xie et al, ${ }^{19}$ and Peguero et al ${ }^{20}$ argued that isolated QRS voltage amplitude combined with QRS duration might enhance diagnostic sensitivity when ECG was used to detect LVH in the previous studies. We analyzed CP criterion, the composite one that is derived by multiplying Cornell voltage criterion and QRS duration, together with Cornell voltage criterion and SL index. The higher correlation coefficient, lower chi-squared values and greater area under the ROC curve of $\mathrm{CP}$ criterion make it the best indicator to evaluate $\mathrm{LVH}$, and this is in accordance with previous studies by Salles et $\mathrm{al}^{21}$ and by Xie et al. ${ }^{19}$ However, subjects from the Salles's study were resistant hypertensives with a prevalence of LVH $87 \%$, which is much higher than the current study.

Even integrating isolated QRS voltage without $Q R S$ duration, Cornell criterion is still superior to SL index in detecting $\mathrm{LVH}^{22}{ }^{22}$ The same findings are detected in the study by Casale et $\mathrm{a}^{23}$ as well. Based on a meta-analysis by Pewsner et al, ${ }^{24}$ the highest sensitivity of electrocardiographic LVH (ECG-LVH) was $68 \%$. Nevertheless, the lowest is only 0 , and the sensitivity in most of the collected studies ranges from $10 \%$ to $30 \%$. By studying different ethnic groups, Rodrigues et $\mathrm{al}^{25}$ and Park et a $1^{18}$ demonstrated that Cornell criterion performs better than SL index, though the sensitivity of both criteria is low.

Of note, an overwhelming majority of Chinese clinicians adopt a gender-specified SL index to diagnose LVH and 
Total population
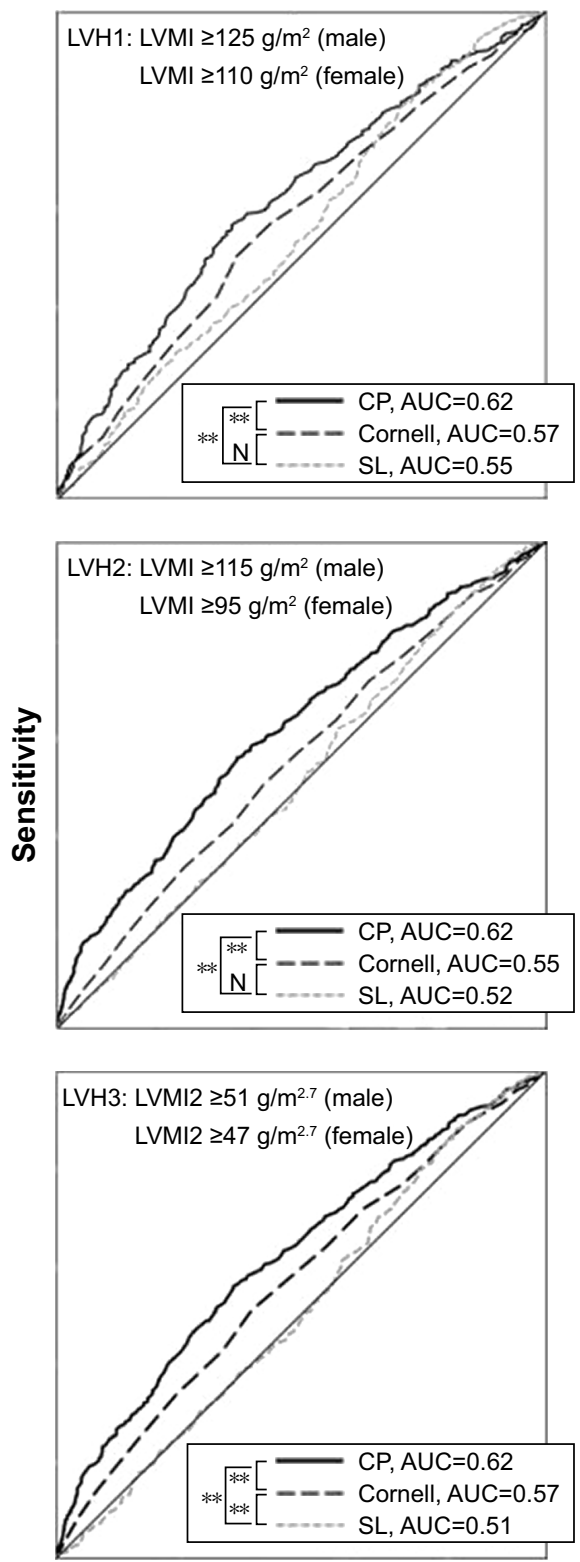

Without hypertension
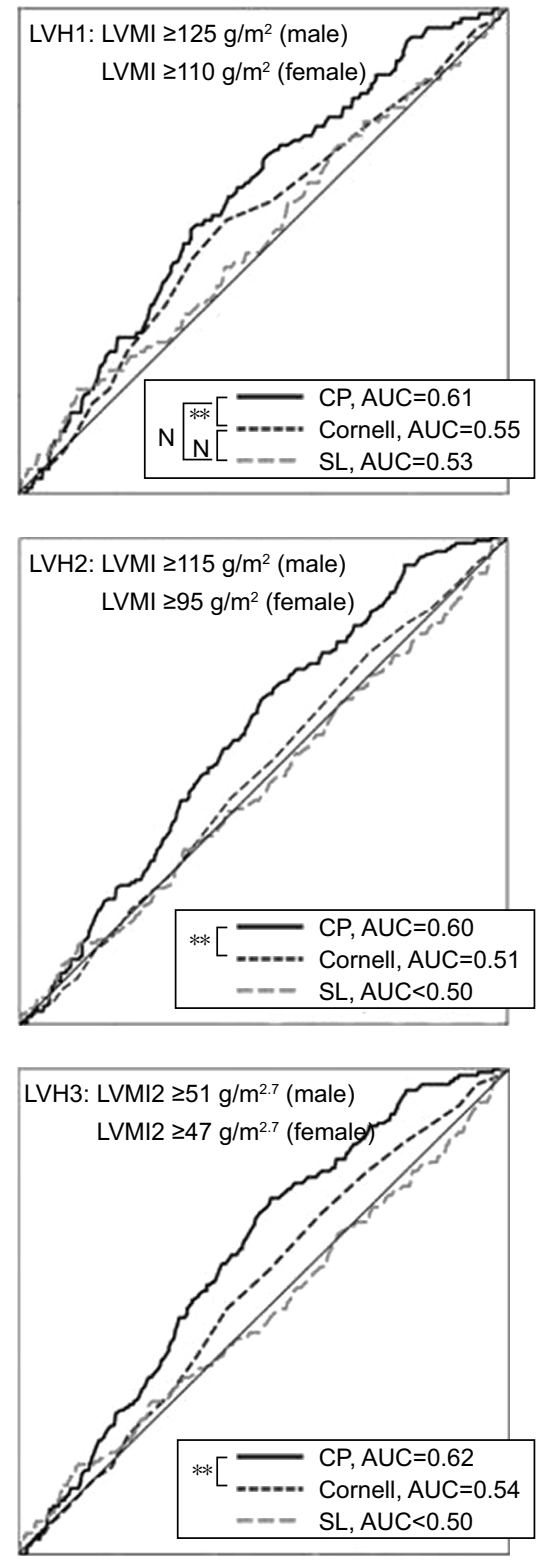

1 - specificity
With hypertension
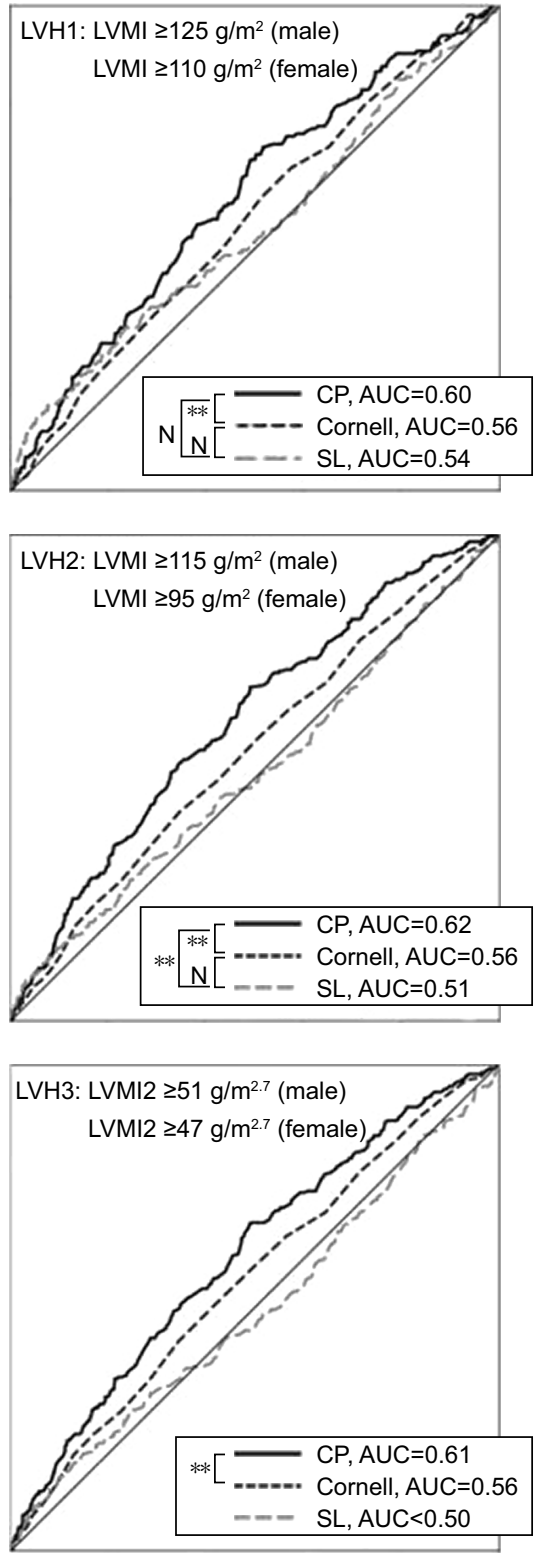

Figure I ROC curve with three electrocardiographic criteria for detecting LVHI, LVH2, and LVH3, the ROC curve for defining LVHI using LVM indexed for BSA $(L V M I) \geq 125 \mathrm{~g} / \mathrm{m}^{2}$ in males and $\geq 110 \mathrm{~g} / \mathrm{m}^{2}$ in females; the ROC curve for defining LVH2 using LVM indexed for BSA (LVMI) $\geq 1 \mathrm{I} 5 \mathrm{~g} / \mathrm{m}^{2}$ in $\mathrm{males}$ and $\geq 95 \mathrm{~g} / \mathrm{m}^{2}$ in females; the ROC curve for defining LVH3 using LVM indexed for BSA (LVMI2) $\geq 5 \mathrm{I} \mathrm{g/m} \mathrm{m}^{2.7}$ in males and $\geq 47 \mathrm{~g} / \mathrm{m}^{2.7}$ in females. $\mathrm{N}$ indicates $P>0.05$ and $* *$ indicates $P<0.0 \mathrm{I}$.

Abbreviations: AUC, area under curve; BSA, body surface area; CP, Cornell Product; LVH, left ventricular hypertrophy; LVM, left ventricular mass; ROC, receiver operating characteristic; SL, Sokolow-Lyon.

the threshold is defined as SV1 + RV5 $\geq 4.0 \mathrm{mV}$ in males and $\geq 3.5 \mathrm{mV}$ in females. ${ }^{26}$ Comparison of SL-China and SL index is shown in Table 4. Though the discrepancies between the two SL criteria and ECHO were still high $(P<0.01)$, SLChina even had larger chi-squared values than commonly used SL index. Over the past 60 years, Chinese clinicians have been keeping faith in the conventional ECG-LVH criterion formed in the $1950 \mathrm{~s} .{ }^{26}$ In addition, a recent investigation by
Antikainen et $\mathrm{al}^{27}$ reported that there is no significant increase in the risk of any cardiovascular events associated with $\mathrm{LVH}$ diagnosed by SL index. Moreover, Wong et $\mathrm{al}^{28}$ and Courand et $\mathrm{al}^{29}$ once proposed to give up SL criterion as well.

The findings of this study have important clinical implications. The expenditure of LVH diagnosed by ECHO is much greater than by ECG. Besides, ECG is cheaper and more convenient in routine clinical practice than $\mathrm{ECHO}$ or 
magnetic resonance imaging. Generally, ECHO is used for correct diagnosis of LVH in inpatients rather than to screen LVH in community or outpatients. $\mathrm{LVH}$ is a common hypertensive TOD. It has significant association with events related to cardiovascular diseases. Therefore, it is very important to diagnose LVH. As the diagnostic accuracy of the SL criterion is very low, Cornell criterion, especially CP criterion, should be implemented in routine clinical practice. Okin et al successfully applied CP to detect LVH in the LIFE study. Because the algorithm of CP criterion is slightly complex, it is strongly recommended to adapt this algorithm to the inbuilt software, in order to automatically offer those indices to physicians and decision-makers. Considering the differences between LVH electrocardiographic criteria in their ability to detect LV, CP criterion is recommended.

It is noteworthy that the study results are derived from a population-based cross-sectional study. Therefore, we aim at investigating the accuracy of different ECG-based formulas in estimating cardiac hypertrophy rather than the prognostic value of those formulas for predicting future cardiovascular events and mortality. With the ongoing follow-up, the prognostic data will be provided in the near future.

The findings of the present study need to be interpreted within the context of its limitations. First, we only applied conventional echocardiograph to define $\mathrm{LVH}$, without using some novel technologies, such as tissue Doppler imaging or speckle tracking. But our conventional measurements are also widely applied in the routine clinical practice. Second, though some ECG measurements were repeated for some cases with large discrepancies, we did not perform the analysis for the day-to-day variability of measurements.

\section{Conclusion}

In summary, by comparing echocardiographic-LVH with ECG-LVH in a community-based cohort, it is indicated that $\mathrm{CP}$ criterion performs better than Cornell voltage criterion and SL index. CP may substitute the SL index to detect LVH, particularly in China.

\section{Acknowledgments}

We would like to express our gratitude to all those who participated in the Northern Shanghai Study. We also thank Yuyan Lu, Hongwei Ji, Ximin Fan, Kai Wang, and Bhavana Rajbanshi for their contribution and valuable advice. This analysis is taken from the Northern Shanghai Study, which receives financial support from the Shanghai municipal government (Grant IDs 2013ZYJB0902 and 15GWZK1002). Dr Yi Zhang was supported by the National Nature Science
Foundation of China (Grant IDs 81300239 and 81670377). The preliminary results of our research were presented orally at the ESH conference, and the abstract was published in the Journal of Hypertension. The hyperlink is: https://insights. ovid.com/crossref?an=00004872-201609001-00424.

\section{Author contributions}

Original data was provided by Wei Zhang, Yiwu Zhou, Bin Bai, Shikai Yu, Jing Xiong, Chen Chi, Jiadela Teliewubai and Jue Li for this study. Methods and protocol were formulated and designed by Jacques Blacher, Yi Zhang and Yawei Xu. Manuscript was drafted by Wei Zhang and Yiwu Zhou. All authors contributed to data analysis, drafting and revising the article, gave final approval of the version to be published, and agree to be accountable for all aspects of the work.

\section{Disclosure}

The authors report no conflicts of interest in this work.

\section{References}

1. Mancia G, Rosei EA, Cifkova R. European Society of HypertensionEuropean Society of Cardiology guidelines for the management of arterial hypertension. Eur Heart J. 2003;34(28):2159-2219.

2. Bluemke DA, Kronmal RA, Lima JA, et al. The relationship of left ventricular mass and geometry to incident cardiovascular events: the MESA (multi-ethnic study of atherosclerosis) study. J Am Coll Cardiol. 2008;52(25):2148-2155.

3. Narayanan K, Reinier K, Teodorescu C, et al. Electrocardiographic versus echocardiographic left ventricular hypertrophy and sudden cardiac arrest in the community. Heart Rhythm. 2014;11(6):1040-1046.

4. Hsieh BP, Pham MX, Froelicher VF. Prognostic value of electrocardiographic criteria for left ventricular hypertrophy. Am Heart J. 2005; 150(1):161-167.

5. Verdecchia P, Schillaci G, Borgioni C, et al. Prognostic significance of serial changes in left ventricular mass in essential hypertension. Circulation. 1998;97(1):48-54.

6. Hancock EW, Deal BJ, Mirvis DM, et al. American Heart Association Electrocardiography and Arrhythmias Committee, Council on Clinical Cardiology; American College of Cardiology Foundation; Heart Rhythm Society. AHA/ACCF/HRS recommendations for the standardization and interpretation of the electrocardiogram: Part V: electrocardiogram changes associated with cardiac chamber hypertrophy: a scientific statement from the American Heart Association Electrocardiography and Arrhythmias Committee, Council on Clinical Cardiology; the American College of Cardiology Foundation; and the Heart Rhythm Society. Endorsed by the International Society for Computerized Electrocardiology. J Am Coll Cardiol. 2009;53(11): 992-1002.

7. Sokolow M, Lyon TP. The ventricular complex in left ventricular hypertrophy as obtained by unipolar precordial and limb leads. Am Heart $J$. 1949;37(2):161-186.

8. Okin PM, Roman MJ, Devereux RB, Kligfield P. Electrocardiographic identification of increased left ventricular mass by simple voltageduration products. J Am Coll Cardiol. 1995;25(2):417-423.

9. Crow RS, Prineas RJ, Rautaharju P, Hannan P, Liebson PR. Relation between electrocardiography and echocardiography for left ventricular mass in mild systemic hypertension (results from treatment of mild hypertension study). Am J Cardiol. 1995;75(17):1233-1238. 
10. Bacharova L, Szathmary V, Kovalcik M, Mateasik A. Effect of changes in left ventricular anatomy and conduction velocity on the QRS voltage and morphology in left ventricular hypertrophy: a model study. J Electrocardiol. 2010;43(3):200-208.

11. Sundström J, Lind L, Arnlöv J, Zethelius B, Andrén B, Lithell HO. Echocardiographic and electrocardiographic diagnoses of left ventricular hypertrophy predict mortality independently of each other in a population of elderly men. Circulation . 2001;103(19):2346-2351.

12. Kossmann CE, Brody DA, Burch GE, et al. Recommendations for standardization of leads and of specifications for instruments in electrocardiography and vectorcardiography. Circulation. 1967;35(3):583-602.

13. Casale PN, Devereux RB, Kligfield P, et al. Electrocardiographic detection of left ventricular hypertrophy: development and prospective validation of improved criteria. J Am Coll Cardiol. 1985;6(3):572-580.

14. Molloy TJ, Okin PM, Devereux RB, Kligfield P. Electrocardiographic detection of left ventricular hypertrophy by the simple QRS voltageduration product. J Am Coll Cardiol. 1992;20(5):1180-1186.

15. Lang RM, Badano LP, Mor-Avi V, et al. Recommendations for cardiac chamber quantification by echocardiography in adults: an update from the American Society of Echocardiography and the European Association of Cardiovascular Imaging. Eur Heart J Cardiovasc Imaging. 2015;16(3):233-271.

16. de Simone G, Devereux RB, Daniels SR, Koren MJ, Meyer RA, Laragh JH. Effect of growth on variability of left ventricular mass: assessment of allometric signals in adults and children and their capacity to predict cardiovascular risk. J Am Coll Cardiol. 1995;25(5): 1056-1062.

17. de Simone G, Daniels SR, Devereux RB, et al. Left ventricular mass and body size in normotensive children and adults: assessment of allometric relations and impact of overweight. J Am Coll Cardiol. 1992;20(5): 1251-1260

18. Park JK, Shin JH, Kim SH, et al. A comparison of Cornell and SokolowLyon electrocardiographic criteria for left ventricular hypertrophy in Korean patients. Korean Circ J. 2012;42(9):606-613.

19. Xie L, Wang Z. Correlation between echocardiographic left ventricular mass index and electrocardiographic variables used in left ventricular hypertrophy criteria in Chinese hypertensive patients: PP.29.149. Hellenic J Cardiol. 2010;51(5):391-401.
20. Betjeman TJ, Rigales L, Hoffman I, Saberio LP, Jorge P. Electrocardiographic criteria for the diagnosis of left ventricular hypertrophy. J Am Coll Cardiol. 2017;70(14):1829-1831.

21. Salles G, Leocádio S, Bloch K, Nogueira AR, Muxfeldt E. Combined QT interval and voltage criteria improve left ventricular hypertrophy detection in resistant hypertension. Hypertension. 2005;46(5):1207-1212.

22. Chapman N, Mayet J, Ozkor M, Lampe FC, Thom SA, Poulter NR. QT intervals and QT dispersion as measures of left ventricular hypertrophy in an unselected hypertensive population. Am J Hypertens. 2001; 14(5 Pt 1):455-462.

23. Casale PN, Devereux RB, Alonso DR, Campo E, Kligfield P. Improved sex-specific criteria of left ventricular hypertrophy for clinical and computer interpretation of electrocardiograms: validation with autopsy findings. Circulation. 1987;75(3):565-572.

24. Pewsner D, Jüni P, Egger M, Battaglia M, Sundström J, Bachmann LM. Accuracy of electrocardiography in diagnosis of left ventricular hypertrophy in arterial hypertension: systematic review. BMJ. 2007; 335(7622):711.

25. Rodrigues SL, D’Angelo L, Pereira AC, Krieger JE, Mill JG. Revision of the Sokolow-Lyon-Rappaport and Cornell voltage criteria for left ventricular hypertrophy. Arq Bras Cardiol. 2008;90(1):46-53.

26. Huang W. [Clinical electrocardiography]. People's Medical Publishing House. 1956. Chinese.

27. Antikainen RL, Peters R, Beckett NS, et al. Left ventricular hypertrophy is a predictor of cardiovascular events in elderly hypertensive patients: hypertension in the very elderly trial. J Hypertens. 2016;34(11): 2280-2286.

28. Wong KY, Lim PO, Wong SY, Macwalter RS, Struthers AD, Macdonald TM. Does a prolonged QT peak identify left ventricular hypertrophy in hypertension? Int J Cardiol. 2003;89(2-3):179-186.

29. Courand PY, Lantelme P, Gosse P. Electrocardiographic detection of left ventricular hypertrophy: time to forget the Sokolow-Lyon index? Arch Cardiovasc Dis. 2015;108(5):277-280.
Clinical Interventions in Aging

\section{Publish your work in this journal}

Clinical Interventions in Aging is an international, peer-reviewed journal focusing on evidence-based reports on the value or lack thereof of treatments intended to prevent or delay the onset of maladaptive correlates of aging in human beings. This journal is indexed on PubMed Central, MedLine,

\section{Dovepress}

CAS, Scopus and the Elsevier Bibliographic databases. The manuscript management system is completely online and includes a very quick and fair peer-review system, which is all easy to use. Visit http://www.dovepress. com/testimonials.php to read real quotes from published authors. 